\title{
The Contribution of Sucrose Esters to Tobacco Smoke Composition *
}

\author{
by W. S. Scblotzhauer, R. F. Severson and R. M. Martin
}

Tobacco Safety Researcb Unit, Agricultural Research Service,

United States Department of Agriculture, Athens, Georgia, U.S.A.

\section{SUMMARY}

Sucrose esters, principally the 6-O-acetyl-2,3,4-tri- $O$ (3-methylvaleryl)- $\alpha$ - $D$-glucopyranosyl- $\beta$ - $D$-fructofuranoside isomer, isolated from the cuticular waxes of green T.I. 165 tobacco leaf, were evaluated as enhancers of 3-methylvaleric acid in the smoke of a tobacco deficient in this important flavor compound. Analyses of the products from semi-micro pyrolyses of sucrose and isolated sucrose esters, over a temperature range of $250^{\circ} \mathrm{C}$ $-850^{\circ} \mathrm{C}$, showed that free sucrose produced 5-hydroxymethylfurfural as the major component, whereas the ester isolate yielded 3-methylvaleric acid and lesser amounts of isomeric $\mathrm{C}_{4}$ and $\mathrm{C}_{3}$ aliphatic acids. Incorporation of sucrose ester isolate of T.I. 165 leaf into cigarettes prepared from flue-cured NC 2326 tobacco, the smoke of which is essentially devoid of 3-methylvaleric acid, resulted in a total particulate matter with enhanced levels of this compound. The data indicated that addition of approximately $2 \mathrm{mg}$ of sucrose ester isolate per cigarette produced levels of 3-methylvaleric acid in the smoke of NC 2326 cigarettes that were comparable to levels observed in the smoke from cigarettes containing all T.I. 165 or blended Turkish tobacco.

\section{ZUSAMMENFASSUNG}

Es wird angenommen, daß aus den Kutikularwachsen des grūnen Blattgutes der Zuchtsorte T.I. 165 isolierte

\footnotetext{
* Received: 9th July 1985 - atcepted: 25th February 1986.

Presented, in part, at the 38th Tobacco Chemista' Research Conference, Atlanta, Georgia, 1984.
}

Saccharoseester - vor allem das Isomer 6-O-Acetyl2,3,4-tri- $O$-(3-methylvaleryl)- $\alpha$-D-glucopyranosyl- $\beta$-Dfructofuranosid - die Bildung von 3-Methylvaleriansäure im Rauch eines Tabaks begünstigen, der diesen wichtigen Aromastoff selbst nicht enthält. Zur näheren Untersuchung wurden Saccharose und isolierte Saccharoseester einer Halbmikropyrolyse in dem Temperaturbereich zwischen $250^{\circ} \mathrm{C}$ und $850^{\circ} \mathrm{C}$ unterzogen. Die Analyse der Zersetzungsprodukte zeigte, daß sich aus freier Saccharose hauptsächlich 5-Hydroxymethylfurfural bildet, wāhrend aus dem isolierten Ester 3-Methylvaleriansâure und in kleineren Mengen isomere aliphatische Säuren $\left(C_{4}\right.$ und $\left.C_{3}\right)$ entstehen. Wenn der aus dem Blattgut der Sorte T.I. 165 isolierte Saccharoseester Zigaretten aus „flue-cured *-Tabak der Sorte NC 2326 zugesetzt wurde, in dessen Rauch sich im wesentlichen keine 3-Methylvaleriansäure befindet, zeigten sich in der Gesamtpartikelphase erhöhte Werte für diese Verbindung. Der Rauch von Zigaretten aus Tabak der Sorte NC 2326, dem ungefähr $2 \mathrm{mg}$ des isolierten Saccharoseesters je Zigarette beigemischt worden war, enthielt 3-Methylvaleriansäure in Mengen, die jenen vergleichbar sind, die im Rauch von Zigaretten zu finden sind, die nur aus Tabak der Zuchtsorte T.I. 165 oder nur aus einer Mischung von Orienttabaken bestehen.

\section{RESUME}

Il semble que les esters de saccharose isolés à partir des cires cuticulaires des feuilles de tabac en vert de la variété T.I. 165 - surtout l'isomère 6-O-acétyl-2,3,4-tri$O$-(méthyl-3-valéryl) - $\alpha$-D - glucopyranosyl- $\beta$-D-fructofuranoside - favorisent la formation d'acide méthyl-3 
valérianique dans la fumée d'un tabac qui ne contient pas lui-même cette importante substance aromatique. Pour vérifier cette hypothèse, du saccharose et des esters de saccharose isolés ont été soumis à une semi-micropyrolyse dans un domaine de températures allant de $250^{\circ} \mathrm{C}$ à $850^{\circ} \mathrm{C}$. L'analyse des produits de la décomposition a montré que le saccharose libre conduisait essentiellement à la formation d'hydroxyméthyl-5 furfural tandis que l'ester isolé donnait naissance à de l'acide méthyl-3 valérianique et, en quantités plus réduites, à des acides aliphatiques isomères (en $\mathrm{C}_{4}$ et $\mathrm{C}_{5}$ ). Si l'on ajoute de l'ester de saccharose tiré des feuilles de la variété T.I. 165 à des cigarettes de tabac eflue-cured* de la variété NC 2326, cigarettes dont la fumée ne contient pratiquement pas d'acide méthyl-3 valérianique, ce dernier composé apparaît alors à une concentration plus forte dans la phase particulaire totale. La fumée produite par des cigarettes en tabac de variété NC 2326 auquel on avait mélangé - par cigarette - environ $2 \mathrm{mg}$ d'ester de saccharose préisolé, s'est avérée contenir de l'acide méthyl-3 valérianique en quantités comparables à celles trouvées dans la fumée de cigarettes constituées uniquement de tabac de la variété T.I. 165 ou d'un mélange de tabacs d'Orient.

\section{INTRODUCTION}

Studies by SEverson et al. $(1,2)$ have shown that cuticular waxes from T.I. 165 tobacco, as well as from commercially popular Turkish tobacco varieties, contain 6-O-acetyl-2,3,4-tri-O-(3-methylvaleryl)- $\alpha$-D-glucopyranosyl- $\beta-\dot{D}-f$ fuctofuranoside. This sucrose ester and related isomers are the probable green leaf precursors of the corresponding tetraacylglucopyranoside isolated from cured Turkish tobacco by SCHUMACHER (3) and RIVERs (4). These sucrose esters are the precursors of the three compounds, isobutyric, 3-methylbutyric, and 3-methylvaleric acids, which have been identified by STEDMAN et al. (5) as characteristic of Turkish tobacco smoke composition. These acids are important contributors to the distinct organoleptic properties of such smoke, since a mixture of 3-methylbutyric and 3-methylvaleric acid can be substituted for Turkish tobacco in blended cigarettes $(6,7)$. Saponification (8) of sucrose esters from T.I. 165 tobacco yielded $0.08,0.41$, and 2.03 moles per sucrose moiety of isobutyric, 3-methylbutyric, and 3-methylvaleric acids, respectively. The corresponding values for sucrose esters isolated from NC 2326 tobacco were $0.31,1.19$, and 0.06 , respectively.

The present study was designed to determine the contribution of sucrose esters to 3-methylvaleric acid levels in cigarette smoke and to investigate the practicality of altering the smoke composition and organoleptic properties of a popular U.S. flue-cured tobacco (North Carolina 2326) by addition of varying amounts of these esters. The thermal decomposition products of both unesterified sucrose and isolated sucrose esters were determined over a range of temperatures known to oc- cur within a burning cigarette. The amounts of 3-methylvaleric acid in total particulate matter from cigarettes, composed of all flue-cured NC 2326 tobacco, were determined before and after addition to the cigarettes of varying amounts of a sucrose ester isolate extracted from green T.I. 165 tobacco.

\section{EXPERIMENTAL *}

\section{Isolation of Sucrose Esters}

Cuticular components of fully extended green bud leaves of T.I. 165 tobacco, grown at the Coastal Plains Experiment Station, United States Department of Agriculture, Tifton, Georgia, were removed at the field location by dipping the leaves into methylene chloride, according to SEvErson et al. (2). The wash was filtered through anhydrous sodium sulfate, and transported with dry ice refrigeration to the laboratory.

Isolation of a sucrose ester fraction was accomplished according to a method previously reported (8). After removal of methylene chloride (in vacuo, $40^{\circ} \mathrm{C}$ ), the residue was partitioned between hexane and $80 \%$ methanol-water. A chloroform soluble fraction obtained from the methanol-water soluble residue was repetitively chromatographed on a Sephadex LH-20 column $(1.37 \mathrm{~cm}$ inside diameter $\times 110 \mathrm{~cm})$ until a $95 \%$ pure fraction of sucrose ester isomers was obtained. The predominant isomer had mass spectral characteristics $\left(M^{+}, \mathrm{m} / \mathrm{e} 678\right)$ indicative of one acetyl and three 3-methylvaleryl groups on the glucose moiety of sucrose.

\section{Pyrolysis of Sucrose and Sucrose Ester Isolates}

Sucrose (Baker analyzed reagent grade) was pyrolyzed in $5 \mathrm{mg}$ quantities in quartz tubes, using a semi-micro platinum coil pyroprobe assembly, previously described $(9,10)$. Pyrolyses were performed, in a stream of dry nitrogen $(15 \mathrm{ml} / \mathrm{min})$, by elevating the coil to the desirable temperature (range $350^{\circ} \mathrm{C}-850^{\circ} \mathrm{C}$ ) in $8 \mathrm{~ms}$ and holding for $10 \mathrm{~s}$. Pyrolyzate material was eluted from the trapping system into Reacti-vials (Piexce Chemical Co.) with $50 \mu \mathrm{l}$ of solvent (acetone/chloroform $(2 / 1)$, each redistilled in glass) containing 1-tetradecanol $(1 \mu \mathrm{g} / \mu \mathrm{l}(\mathrm{w} / \mathrm{v}))$ as internal standard.

A solution of the isolated sucrose esters was taken to dryness under nitrogen, the residue weight was determined, and the residue was redissolved in methylene chloride (redistilled in glass) to a concentration of $0.2 \mathrm{mg}$ residue $/ 20 \mu \mathrm{l}$ solvent. Pyrolyses were performed as for sucrose; however, for convenience, the sucrose esters were applied as solution on a platinum ribbon pyroprobe assembly in place of the coil assembly. Aliquots of the sucrose ester solution, equivalent to $5 \mathrm{mg}$ residue, were applied to the ribbon with a

\footnotetext{
* Reference to a company or product name does not imply approval or recommendation by the United States Department of Agriculeure.
} 
$10 \mu \mathrm{l}$ syringe and the solvent was removed by flashing at $75{ }^{\circ} \mathrm{C}$ for $2 \mathrm{~s}$, prior to probe insertion into the pyrolysis apparatus. Pyrolyzates were recovered as for sucrose.

\section{Glass Capillary Gas Chromatography}

Pyrolyzate components were converted to their trimethylsilyl derivatives by reaction with an excess of $N, O$ bis(trimethylsilyl)trifluoroacetamide (BSTFA (Pierce Chemical Co.)) at $75^{\circ} \mathrm{C}$ for $30 \mathrm{~min}$. Analyses were performed on a Hewlett-Packard model 5720A gas chromatograph, equipped with flame ionization detector and a single fused silica glass capillary column $(30 \mathrm{~m} \times 0.32 \mathrm{~mm}$ inside diameter) coated with SE-54, according to the procedure of ARRENDALE et al. (11). Gas chromatographic conditions were: $30 \mathrm{~cm} / \mathrm{s}$ carrier gas (hydrogen) flow, 50:1 split injection mode, oven temperature programmed from $50^{\circ} \mathrm{C}$ to $250^{\circ} \mathrm{C}$ at $4^{\circ} \%$ min. Identification of components was based on retention properties of, and co-injection with, authentic compounds. Quantitative determinations were based on response data, using 1-tetradecanol-TMS as internal standard.

\section{Cigarette Smoking Experiments}

Cigarettes prepared from flue-cured tobacco varieties grown in the United States, were provided by the Tobacco Research Laboratory, United States Department of Agriculture, Oxford, North Carolina. Air-cured Burley tobacco and blended Turkish tobacco cigarettes were provided by the Tobacco and Health Research Institute, University of Kentucky, Lexington, Kentucky. All cigarettes were $85 \mathrm{~mm}$, non-filter, and were selected by weight and draw resistance. Cigarettes were conditioned at $60 \%$ relative humidity for $48 \mathrm{~h}$ prior to smoking. The cigarettes were smoked onto glass-fiber filter pads by a Filtrona model 302 8-port smoking machine under standard smoking conditions (12), smoking to a butt length of $23 \mathrm{~mm}$. Three cigarettes were smoked per individual pad. The total particulate matter weights were recorded, the pads were placed in a solution of acetone/chloroform $(2 / 1, v / v)$, and particulates were dissolved under sonification. The solutions were concentrated in vacuo $\left(30^{\circ} \mathrm{C}\right)$ and adjusted to a $5.0 \mathrm{ml}$ volume and a known amount of 1-tetradecanol was added. Trimethylsilylation and subsequent gas chromatographic analyses were performed as described for pyrolyzates.

Selected NC 2326 cigarettes were treated with varying amounts of T.I. 165 sucrose ester isolate, as follows. A solution containing $1.0 \mathrm{mg}$ sugar ester isolate per $10 \mu \mathrm{l}$ methylene chloride was prepared. Cigarettes were divided into groups of three and equivalents of $0.33,1.00$, 1.67 , and $2.33 \mathrm{mg}$ per cigarette were added by inserting a $10 \mu \mathrm{l}$ syringe horizontally into the center of the cigarette rod and injecting the appropriate volume of sol- vent into the middle third of the cigarette. The cigarettes were then re-equilibrated, prior to smoking. Smoke analyses were performed as above.

\section{RESULTS AND DISCUSSION}

The pyrolysis of sucrose has been extensively studied $(10,13,14)$, but was repeated in this experiment to provide baseline data for free sucrose thermal decomposition products and to allow comparison with pyrolysis profiles of sucrose esters, under similar conditions. A profile of the silylated pyrolyzate of sucrose at $550^{\circ} \mathrm{C}$ (Figure 1) is characterized by the formation of 5-hydroxymethylfurfural as predominant product, with lesser yields of furfural and related compounds. No evidence was obtained of the presence of any significant amouts of fatty acids in pyrolyzates of sucrose over the temperature range studied. The maximum yield (Table 1) of 5-hydroxymethylfurfural from sucrose pyrolyzed in nitrogen was obtained at $450^{\circ} \mathrm{C}$, with highest yields occurring between $400^{\circ} \mathrm{C}$ and $600^{\circ} \mathrm{C}$. The organoleptic significance of 5-hydroxymethylfurfural in tobacco smoke is at present unclear, although Perini and Bell (15) have reported this furan as a positive contributor to and indicator of quality of both flue-cured and Turkish tobaccos.

The pyrolysis profile of the sucrose ester isolate from green T.I. 165 tobacco (Figure 2) contains a series of isomeric $\mathrm{C}_{4}$ through $\mathrm{C}_{6}$ aliphatic acids, in addition to the 5-hydroxymethylfurfural derived from the sucrose moiety. Quantitative analyses (Table 2) of these pyrolyzates, over a range of $250^{\circ} \mathrm{C}-850^{\circ} \mathrm{C}$, showed that 3-methylvaleric acid was the compound recovered in greatest amount in all cases, with a maximum range of formation between $400^{\circ} \mathrm{C}$ and $700^{\circ} \mathrm{C}$. These results are consistent with the thermal degradation of sucrose esterified with a predominance of 3-methylvaleryl attachments. The relative distribution of products (Table 3 ) was substantially unaltered over the wide range of pyrolytic temperatures, with 3-methylvaleric acid accounting for $60 \%-67 \%$ of the quantities of principal products identified. The ratio of the isomeric methylbutyric acids also varied insignificantly with pyrolysis temperature. These data suggest that sucrose esters are readily thermally decomposed to a stable pattern of fatty acid isomers. It is reasonable to expect that this behavior would similarly occur within the complex internal thermal profile generated by a burning cigarette. Maximum recoveries of the 5-hydroxymethylfurfural generated from the sucrose portion of the molecule were seen to shift to a higher temperature range $\left(400^{\circ} \mathrm{C}-700^{\circ} \mathrm{C}\right)$, than observed for free sucrose, as the ester linkages would be expected to interfere with the thermal breakdown pathway involved in its formation. Addition of sucrose ester isolate to cigarette tobacco, devoid of these components, would be expected to enhance levels of 3-methylvaleric acid as well as 5-hydroxymethylfurfural in total particulate matter. 
Table 1.

5-Hydroxymethylfurfural in pyrolyzates of sucrose.

\begin{tabular}{c|c}
\hline $\begin{array}{c}\text { Pyrolysis temperature } \\
\left({ }^{\circ} \mathrm{C}\right)\end{array}$ & $\begin{array}{c}\text { Yield of 5-hydroxymethylfurfural } \\
(\mu \mathrm{g} / \mathrm{mg} \text { pyrolyzed })\end{array}$ \\
\hline 350 & 60.9 \\
450 & 82.9 \\
550 & 76.0 \\
650 & 65.9 \\
750 & 47.4 \\
850 & 37.3 \\
\hline
\end{tabular}

Figure 1.

GC-2 proflle of trimethylsilylated pyrolysis products of sucrose $\left(550{ }^{\circ} \mathrm{C}\right)$.

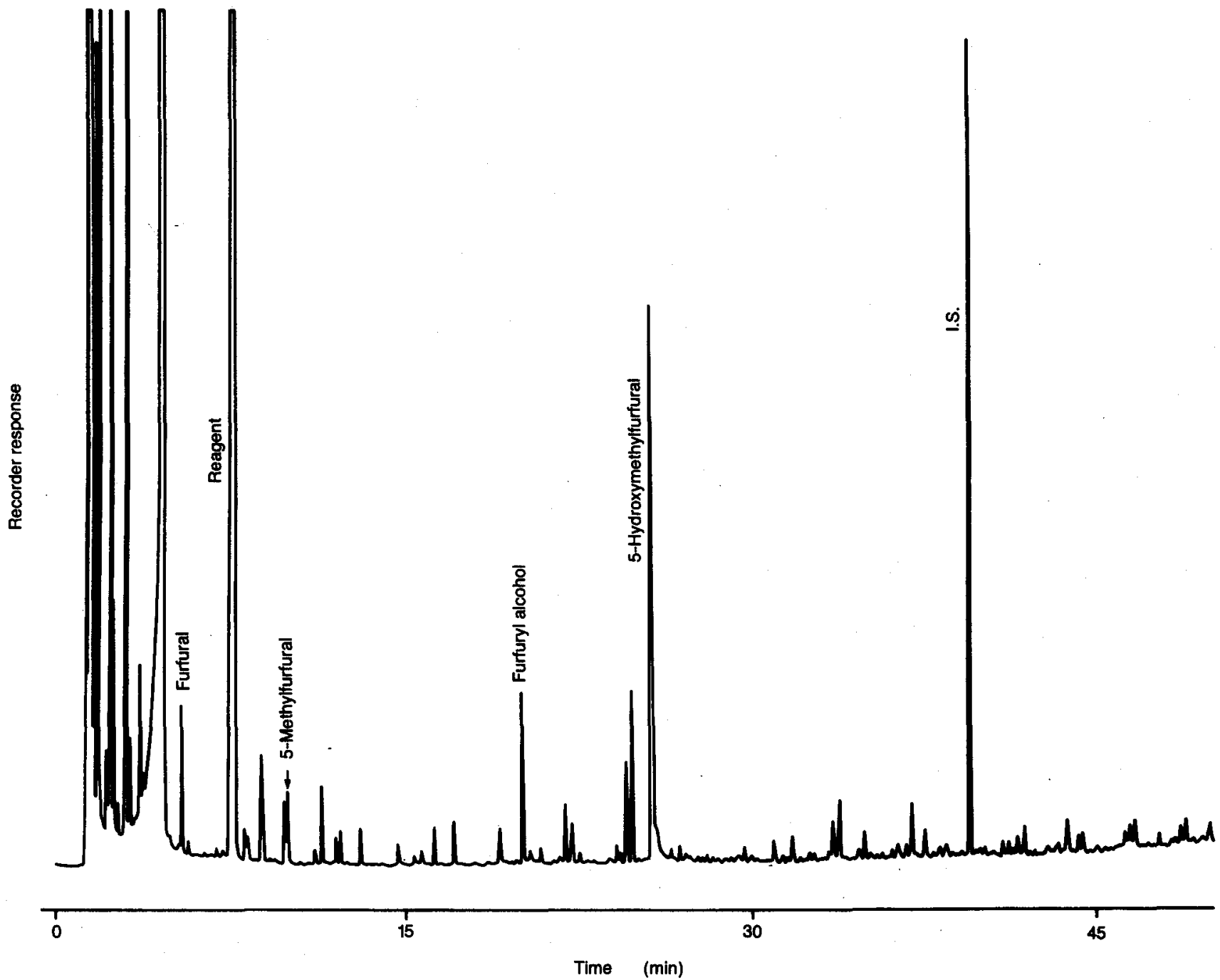


Flgure 2.

GC-2 profile of trimethylsilylated pyrolysis products of sucrose ester Isolate $\left(5500^{\circ} \mathrm{C}\right)$.

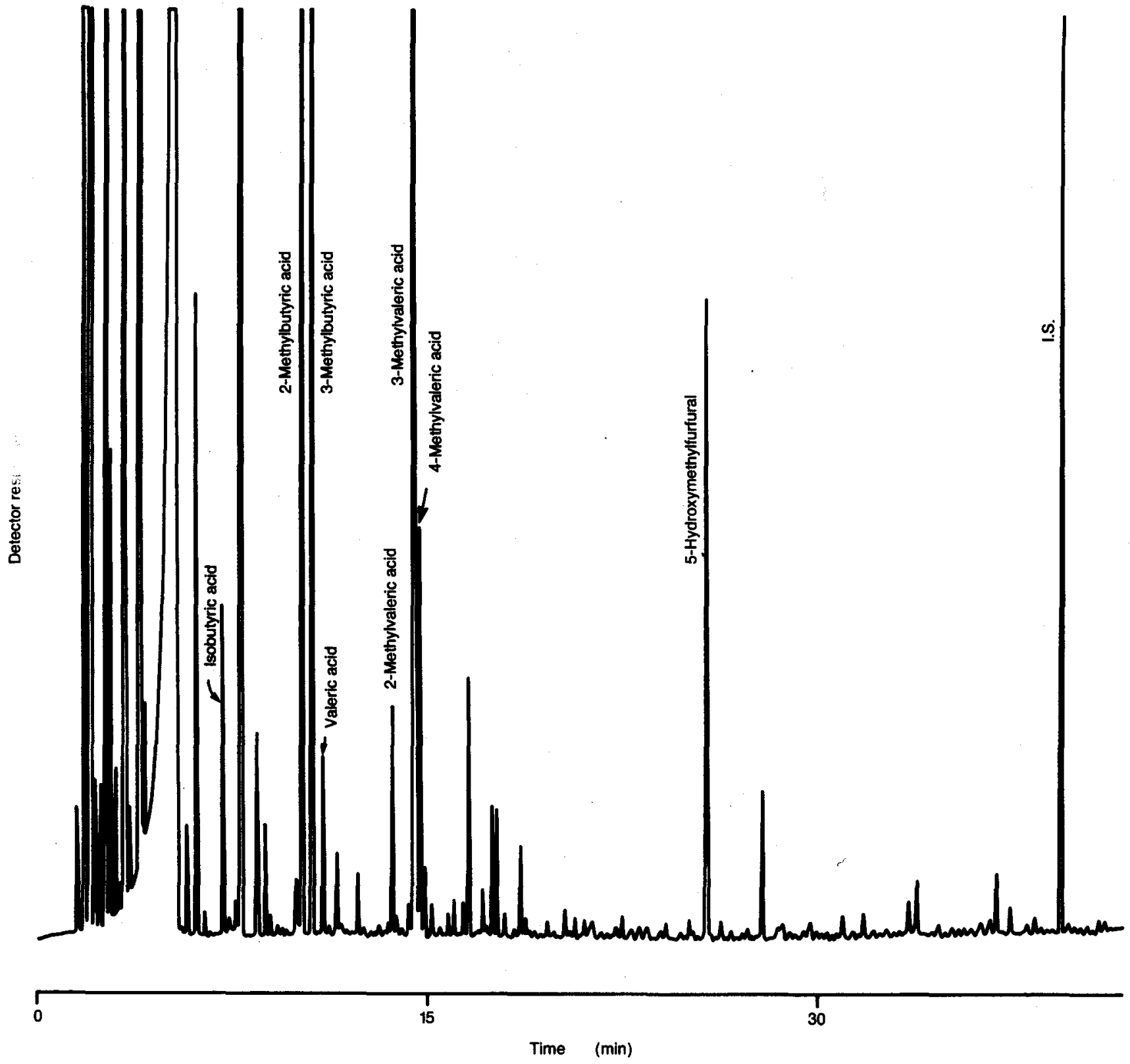


Figure 3.

3-Methylvaleric acid levels in GC-2 profiles of cigarette total particulate matter (TPM).

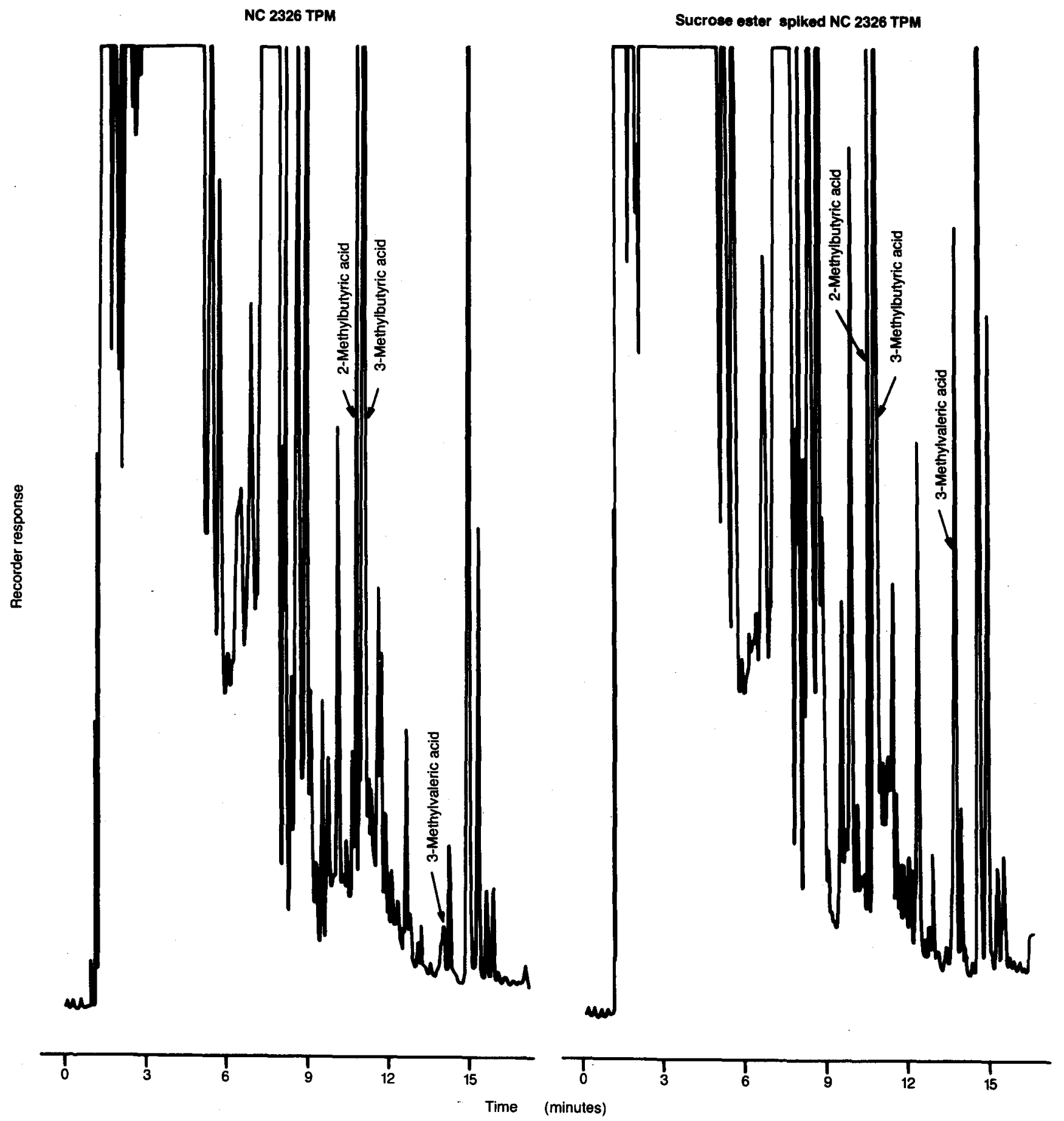


Figure 3 (cont'd.).

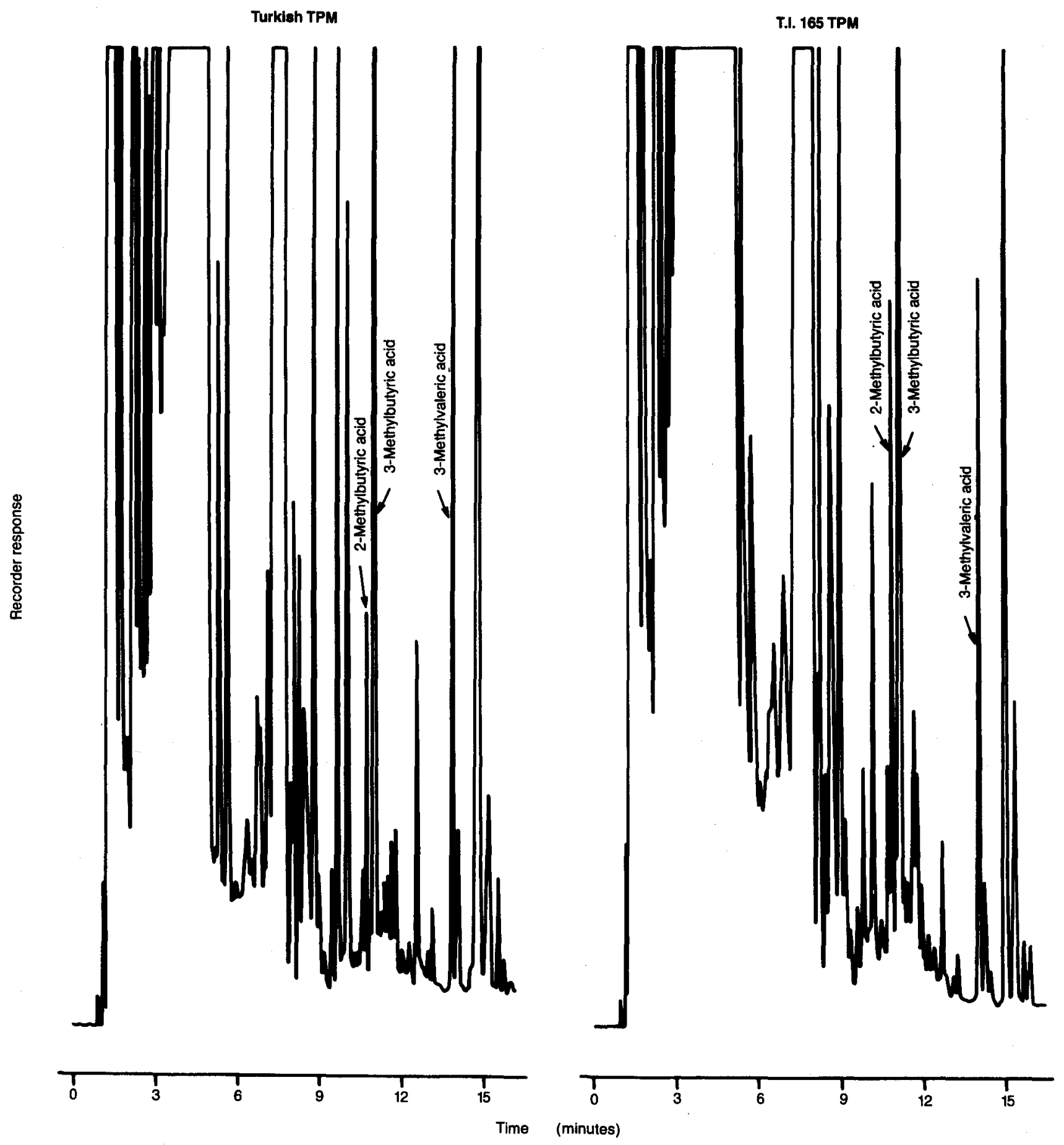


Table 2.

Pyrolysis products ( $\mu \mathrm{g} / \mathrm{mg}$ pyrolyzed) of sucrose esters.

\begin{tabular}{|c|c|c|c|c|c|c|c|}
\hline \multirow{2}{*}{ Component } & \multirow[b]{2}{*}{250} & \multirow[b]{2}{*}{350} & \multicolumn{2}{|c|}{ Pyrolysis temperature } & \multicolumn{2}{|l|}{$\left({ }^{\circ} \mathrm{C}\right)$} & \multirow{2}{*}{850} \\
\hline & & & 450 & 550 & 650 & 750 & \\
\hline Propionic acid & 0.1 & 0.2 & 0.3 & 0.2 & 0.1 & 0.2 & 0.1 \\
\hline Isobutyric acid & 1.5 & 2.6 & 4.1 & 3.3 & 3.6 & 2.2 & 1.0 \\
\hline Butyric acid & 0.3 & 0.8 & 1.2 & 1.1 & 1.0 & 1.0 & 0.4 \\
\hline 2-Methylbutyric acid & 6.3 & 12.2 & 17.8 & 15.4 & 19.8 & 10.2 & 8.9 \\
\hline 3-Methylbutyric acid & 11.7 & 23.3 & 34.3 & 30.0 & 33.6 & 20.2 & 16.5 \\
\hline Valeric acid & 0.2 & 0.4 & 0.7 & 0.6 & 0.3 & 0.5 & 0.4 \\
\hline 2-Methylvaleric acid & 0.1 & 3.0 & 4.2 & 3.9 & 4.4 & 2.5 & 2.0 \\
\hline 3-Methylvaleric acid & 60.8 & 122.4 & 165.2 & 161.8 & 167.8 & 112.2 & 98.2 \\
\hline 4-Methylvaleric acid & 2.4 & 4.3 & 5.9 & 5.9 & 3.6 & 4.4 & 3.6 \\
\hline Hexanoic acid & 0.1 & 0.3 & 0.2 & 0.3 & 0.1 & 0.2 & 0.1 \\
\hline Heptanoic acid & 0.1 & 0.1 & 0.3 & 0.3 & 0.4 & 0.2 & 0.1 \\
\hline Octanoic acid & 0.1 & 0.3 & 0.2 & 0.2 & 0.3 & 0.2 & 0.1 \\
\hline 5-Hydroxymethylfurfural & 8.2 & 26.9 & 38.7 & 33.6 & 40.3 & 22.4 & 14.5 \\
\hline
\end{tabular}

Table 3.

Percentage distrlbution of principal products of sucrose ester pyrolysis.

\begin{tabular}{|c|c|c|c|c|c|c|c|}
\hline \multirow{2}{*}{ Component } & \multicolumn{7}{|c|}{ Pyrolysis temperature } \\
\hline & 250 & 350 & 450 & 550 & 650 & 750 & 850 \\
\hline Isobutyric acid & 1.6 & 1.3 & 1.5 & 1.3 & 1.3 & 1.2 & 0.6 \\
\hline 2-Methylbutyric acld & 6.8 & 6.2 & 6.5 & 5.8 & 7.2 & 5.8 & 6.1 \\
\hline 3-Methylbutyric acid & 12.7 & 11.8 & 12.5 & 11.2 & 12.2 & 11.5 & 11.3 \\
\hline 2-Methylvaleric acid & 0.1 & 1.0 & 1.5 & 1.5 & 1.6 & 1.4 & 1.4 \\
\hline 3-Methylvaleric acid & 66.1 & 62.2 & 60.5 & 60.7 & 60.9 & 63.6 & 67.3 \\
\hline 4-Methylvaleric acid & 2.6 & 2.2 & 2.2 & 2.2 & 1.3 & 2.5 & 2.4 \\
\hline 5-Hydroxymethylfurfural & 8.9 & 13.6 & 14.2 & 12.6 & 14.6 & 12.6 & 9.9 \\
\hline
\end{tabular}

Table 4.

Effect of added sucrose esters (T.I. 165) on 3-methylvaleric acid in total particulate matter (TPM).

\begin{tabular}{|c|c|c|c|c|c|c|}
\hline \multirow[t]{2}{*}{ Cigarette } & \multirow{2}{*}{$\begin{array}{c}\text { Sucrose esters } \\
\text { added } \\
\text { (mg/cig.) }\end{array}$} & \multirow{2}{*}{$\begin{array}{c}\text { TPM } \\
\text { (mg/cig.) }\end{array}$} & \multicolumn{2}{|c|}{$\begin{array}{c}\text { 3-Methylvaleric acid } \\
\text { found }\end{array}$} & \multicolumn{2}{|c|}{$\begin{array}{l}\text { 5-Hydroxymethylfurfural } \\
\text { found }\end{array}$} \\
\hline & & & ( $\mu g / c i g)$. & $(\mu \mathrm{g} / \mathrm{mg}$ TPM $)$ & ( $\mu g / c i g)$. & ( $\mu \mathrm{g} / \mathrm{mg}$ TPM) \\
\hline Turkish blend & 0 & 39 & 161 & 4.12 & 101 & 2.59 \\
\hline T.I. 165 & 0 & 45 & 118 & 2.62 & 199 & 4.42 \\
\hline NC 2326 (control) & 0 & 46 & $<7$ & 0.15 & 160 & 3.48 \\
\hline NC 2326 & 0.33 & 44 & 63 & 1.43 & 228 & 5.18 \\
\hline NC 2326 & 1.00 & 42 & 75 & 1.78 & 229 & 5.45 \\
\hline NC 2326 & 1.67 & 49 & 135 & 2.75 & 303 & 6.18 \\
\hline NC 2326 & 2.33 & 48 & 176 & 3.67 & 283 & 5.89 \\
\hline
\end{tabular}


Evidence for the enhancement of 3-methylvaleric acid in smoke by addition of sucrose ester isolate to cigarettes is given in Figure 3. Profiles of trimethylsilylated total particulate matter (TPM) of blended Turkish tobacco cigarettes and of flue-cured T.I. 165 tobacco cigarettes are characterized by the presence of the isomeric methylbutyric acids and 3-methylvaleric acid. The TPM from unaltered NC 2326 cigarettes is essentially devoid of the latter acid, while the same cigarettes, fortified with isolated sucrose esters, yield a quantity of this component, comparable to Turkish and T.I. $165 \mathrm{cig}$ arettes. Quantitative analyses (Table 4) demonstrated that addition of approximately $2 \mathrm{mg}$ of sucrose ester isolate into NC 2326 cigarettes generated smoke with a 3-methylvaleric acid level similar to levels obtained from Turkish and T.I. 165 tobacco cigarettes. Levels of 3-methylvaleric acid in three repetitive collections and analyses of TPM from the cigarettes were reproducible to $\pm 5 \%$. Recovery of the acid was essentially linear at applications above $1.0 \mathrm{mg}$. Analyses for 5-hydroxymethylfurfural in TPM of the control versus spiked NC 2326 cigarettes also showed increased yields. However, the effects were less discernible as NC 2326, like most flue-cured United States tobaccos, contains substantial amounts of sugars and other carbohydrates (16) that are readily converted to this compound during smoking $(17,18)$. In addition, 5-hydroxymethylfurfural of smoke is partially derived from the thermal decomposition of leaf flavanoid glycosides (19), present in fluecured NC 2326 leaf at relatively high concentrations (20).

The preceding data lead to the conclusion that the principal effect on smoke composition of adding milligram quantities of 3-methylvaleryl-containing sucrose esters to cigarettes would be the enhancement of 3methylvaleric acid. Analyses of TPM of cigarettes of 9 varieties of tobacco (Table 5) showed that only ciga-

\section{Table 5.}

3-Methylvaleric acld In cigarette total particulate matter (TPM).

\begin{tabular}{l|c|c|cr}
\hline Cigarette & $\begin{array}{c}\text { Sucrose } \\
\text { esters* } \\
\text { (mg/cig.) }\end{array}$ & $\begin{array}{c}\text { TPM } \\
\text { (mg/cig.) }\end{array}$ & $\begin{array}{c}\text { 3-Methylvaleric acid } \\
\text { found } \\
(\mu \mathrm{g} / \mathrm{cig} .)\end{array}$ & $(\mu \mathrm{g} / \mathrm{mg}$ TPM) \\
\hline Turkish blend & 4.6 & 39 & 161 & 4.12 \\
T.I. 165 & 2.1 & 45 & 118 & 2.62 \\
NC 2326 & 0 & 44 & $<7$ & $<0.15$ \\
(control) & 0 & 48 & 176 & 3.67 \\
NC 2326 & $2.3^{* *}$ & 36 & $<7$ & $<0.19$ \\
I 35 & 0 & 42 & $<7$ & $<0.16$ \\
T.I. 207 & 0 & 40 & $<7$ & $<0.17$ \\
T.I. 1024 & trace & 37 & $<7$ & $<0.27$ \\
T.I. 1112 & trace & 37 & 0 & 0 \\
Burley & 0 & 26 & $<7$ & $<0.16$ \\
Perique & 0 & 43 & & \\
\hline
\end{tabular}

" Isolated by procedure of Severson et al. (8).

** Added. rettes containing significant amounts of these esters yield measurable quantities of 3-methylvaleric acid in smoke. Addition of an amount of T.I. 165 sucrose esters to NC 2326 cigarettes, equivalent to the amount naturally occurring in T.I. 165 , yielded a smoke disproportionally higher in 3-methylvaleric acid. This result is not surprising, since transfer of a component from one matrix to another might be expected to alter conditions of thermal decomposition. Blended Turkish cigarettes produced a lower than predicted yield of the acid; however, the type of acid groups and their ratios to sucrose moieties vary among tobacco types. Selection of the plant source and method of introduction into cigarette blends, for optimum organoleptic properties of smoke, will require considerable future experimentation.

\section{REFERENCES}

1. Severson, R. F., R. F. Arrendale, O. T. Chortyk and $A$. W. Johnson: The isolation of possible cigarette smoke flavor compounds from green tobacco leaf; Proceedings of the 32nd Southeastern Regional American Chemical Society Meeting, Lexington, Ky., November 4-6, 1981.

2. Severson, R. F., R. F. Arrendale, O. T. Chortyk, A. W. Johnson, D. M. Jackson, G. R. Gwynn, J. F. Chaplin and M. G. Stephenson: Quantitation of major cuticular components from green leaf of different tobacco types; J. Agric. Food Chem. 32 (1984) 566-570.

3. Schumacher, J. N.: The isolation of 6-O-acetyl2,3,4-tri-O-[(+)-3-methylvaleryl]- $\beta$-D-glucopyranose from tobacco; Carbohydr. Res. 13 (1970) 1-8.

4. Rivers, J. M.: Low molecular weight fatty acid sugar esters in Turkish tobacco - Separation by reverse-phase high performance liquid chromatography and spectral characterization; Abstr. Pap. 35th Tobacco Chemists' Research Conference, Winston-Salem, N.C., October 7-9, 1981.

5. Stedman, R. L., D. Burdick and I. Schmeltz: Composition studies on tobacco, XVII. Steam-volatile acidic fraction of cigarette smoke; Tob. Sci. 7 (1963) 166-169.

6. Stedman, R. F., and C. D. Stills: The flavor contribution of Turkish tobacco in blended cigarettes; U.S. Department of Agriculture Report ARS 7343, U.S. Government Printing Office, Washington, D.C., 1964.

7. Stedman, R. L., D. Burdick, W. J. Chamberlain and I. Schmeltz: Composition studies on tobacco, XVIII. Steam-volatile acids in smoke of cigarettes having different organoleptic properties; Tob. Sci. 8 (1964) 79-81. 
8. Severson, R. F., R. F. Arrendale and O. T. Chortyk: Isolation and characterization of the sucrose esters of the cuticular waxes of green tobacco leaf; Abstr. Pap. 37th 'Tobacco Chemists' Research Conference, Washington, D.C., October 10-13, 1983.

9. Thome, F. A., G. W. Young and W. C. Hamlin, Jr.: Applications of pyrolysis - gas chromatography mass spectroscopy to tobacco chemistry; CORESTA Information Bulletin 1982, Special Issue, p. 22.

10. Schlotzhauer, W. S., R. F. Arrendale and O. T. Chortyk: The rapid pyrolytic characterization of tobacco leaf carbohydrate material; Beitr. Tabakforsch. Int. 13 (1985) 74-80.

11. Arrendale, R. F., R. F. Severson and O. T. Chortyk: Simple alternative method for preparing high quality fused silica SE-54 wcot capillary columns; J. High Resolut. Chromatogr. Chromatogr. Commun. 6 (1983) 436-440.

12. Pillsbury, H. C., C. C. Bright, K. J. O'Connor and F. W. Irish: Tar and nicotine in cigarette smoke; J. Assoc. Off. Anal. Chem. 52 (1969) 458-462.

13. Gardiner, D.: The pyrolysis of some hexoses and derived di-, tri-, and poly-saccharides; J. Chem. Soc. (Lond.) Section C 1966, 1473-1476.

14. Johnson, R. F., E. D. Alford and G. W. Kinzer: Formation of sucrose pyrolysis products; J. Agric. Food Chem. 17 (1969) 22-24.

15. Perini, F. R., and J. H. Bell: Determination of 5-hydroxymethylfurfural in tobacco as a measure of browning and quality; Abstr. Pap. 37th Tobacco Chemists' Research Conference, Washington, D.C., October 10-13, 1983.
16. Tso, T. C.: Physiology and biochemistry of tobacco plants; Dowden, Hutchinson and Ross, Inc., Stroudsburg, $\mathrm{Pa}$, 1972.

17. Ishiguro, S., and S. Sugawara: Gas chromatographic analysis of cigarette smoke by trimethylsilylation method; Beitr. Tabakforsch. Int. 9 (1978) 218221.

18. Saint-Jalm, Y.: Qualitative analysis of the hydroxyl fraction of cigarette smoke; Ann. Tab. (section 1) $18(1980-81)$ 41-48.

19. Zane, A., and S. H. Wender: Pyrolysis products of rutin, quercetin, and chlorogenic acid; Tob. Sci. 7 (1963) 21-23.

20. Schlotzhauer, W. S., R. M. Martin, M. E. Snook and R. E. Williamson: Pyrolytic studies on the contribution of tobacco leaf constituents to the formation of smoke catechols; J. Agric. Food Chem. 30 (1982) 372-374.

\author{
Authors' address: \\ Tobacco Safety Researcb Unit, \\ Richard B. Russell Agricultural Research Center, \\ South Atlantic Area Agricultural Research Service, \\ U.S. Department of Agriculture, \\ College Station Road, \\ P.O. Box 5677 , \\ Athens, Georgia, 30613, U.S.A.
}

